\title{
Food adulteration and contamination in India: occurrence, implication and safety measures
}

\author{
R. T. Gahukar \\ Arag Biotech Pvt. Ltd., Plot 220, Reshimbag, Nagpur 440009, India \\ *Corresponding authorE-mail: rtgahukar@gmail.com
}

Copyright $\odot 2014$ R. T. Gahukar. This is an open access article distributed under the Creative Commons Attribution License, which permits unrestricted use, distribution, and reproduction in any medium, provided the original work is properly cited.

\begin{abstract}
In India, adulteration and contamination are encountered in food consumed at the household level, in the food service establishments and business firms, and also when sold as street foods. Non-permitted colors are the most common additives to foods. Contamination of mycotoxins, metals and pesticides in daily foods and milk has been found highly toxic and carcinogenic, and about $70 \%$ of deaths are supposed to be of food-borne origin. In this paper, food safety measures are emphasized with an objective of prevention of health hazards and strengthening of regulatory system. It is possible to prevent food adulteration and contamination if people are made aware of health hazards. If food inspectors are vigilant and active, the risk of food toxicity can be minimized at all levels of food supply and consumption. Further, simple measures can prevent further complications, particularly those caused by microbiological contaminants. Fatal diseases and health hazards prevalent in India can be minimized and consumers can live happily with good health. The social life in the communities is strengthened resulting in less expense on health related problems. Citizens aware of food adulteration and contamination can arrange camps/campaigns through local bodies and safe food can be the goal for all concerned.
\end{abstract}

Keywords: Food Adulterants And Contaminants, Mycotoxins, Food Safety, Preventive Measures, India.

\section{Introduction}

Food should be without or only with acceptable and safe levels of adulterants, contaminants or any other substances that may make food hazardous to health. Also, such food can deprive nutrients essential for proper body growth and development [27]. Therefore, health hazards related to foods and food products are considered to be a major problem particularly in developing and less-developed countries [11, 41]. In India, food safety is a growing problem with rampant instances of adulteration and contamination of essential foods that can be a potential source of disease infection or toxic poisoning. Food spoilage occurs mostly during handling from the primary producers to the consumers (e.g. food production, processing, packaging, distribution, storage, cooking or serving). Adulterants (non-nutritious substances) are intentionally/deliberately added or unintentionally enter into food. Similarly, presence of harmful chemicals or microorganisms including those unaffected by thermal processing is common. Mycotoxins such as, aflatoxins, ochratoxins, fumonisins, zeralenone, patulin, and trichothecenes produced by moulds are found in food supply chain. At community level, serious outbreaks of food-borne diseases have been reported from time to time. However, consumers do not have knowledge/information probably because impact of the contamination on human health is apparent only after prolonged exposure. At national level, globalization in food trade has been introduced as it offers many benefits to consumers by the way of accessibility, affordability and safety of a variety of high quality foods. Consequently, food export has increased in recent years but poses certain challenges concerning food toxicity because integration of the privatization and liberalization in the Indian trade has changed the pattern of food production and consumption. Considering current situation of food toxicity and poisoning due to consumption of adulterated or contaminated food and food products, I have compiled information and have suggested certain practical preventive measures that can be adopted by consumers even in poor countries. 


\section{Occurrence}

\subsection{Food adulteration}

Consumers are not often aware of adulteration particularly in the pre-packaged food and the food that is categorized as "loose" (e.g. without any branding or packaging). This has relevance to the illiterate consumers who get often confused about the quality norms of permitted additives and become victim of irregularities or malpractices in the market. For example, cereals and pulses with sand, gravels, stones, earth or talc are sold in the open market. Healthy sorghum and corn grains are mixed with moldy grains containing fumonicin toxin [3, 19]. The poor quality cardamoms (from which essential oils have been extracted) are mixed with good quality green cardamoms, and red pepper powder is adulterated with colored saw dust in the weekly markets [18]. Black pepper seeds are adulterated with papaya seeds, grass seeds (coated with charcoal dust) or mineral oil. The split grains or flour of pigeon pea (Cajanus cajan) or chick pea (Cicer arietinum) are adulterated with grass pea (Lathyrus sativus) while preparing snacks or meals. There have been reports of consumption of wheat/millet grains mixed with buck wheat (Polygonatum fagopyrum) flour, or seeds of Crotalaria spp. containing toxic alkaloids [4, 19]. Oils and fats containing butylated hydroxyanisole or butylated hydroxyl toluene are mixed with edible oils. From the point of nutrition, the mixing of rancid oil in edible oils destroys vitamins A and E [27]. Admixture of oleomargarine (a product of beef fat) in butter and gelatin, and formaldehyde in milk are common adulterants [18].

A systemic fungicide (benomyl) is applied to vegetables to inhibit the growth of microorganisms and to avoid spoilage. The wax (containing morpholine as a solvent and emulsifier) is spread on fruits to retain moisture, prevent bursting and physical damage, enhances appearance and to extend storage period/shelf life. However, the wax content in the market samples is below the Acceptable daily intake (ADI) of 2.0-3.6 ug/kg body weight/day [4]. Unripe fruits are artificially ripened with ethylene to retain firmness and to give ripening appearance [35]. Powder of calcium carbonate containing traces of arsenic and phosphorus is applied to fruits; fruits and vegetables are plumped up with injection of hormone 'oxytocin' to retain freshness, and colored water is injected into water melon to impart redness to pulp [35]. According to the Ministry of Public Health, oxytocin is being rampantly used and is considered yet safe because there are no deaths from consumption of treated fruits.

Many food commodities containing none permitted colors (NPC) are associated with human diseases [3]. Fruit samples collected from the market showed the NPC content up to $730 \mathrm{ppm}$ which exceeded the statutory limit [3]. Sudershan et al. [40] reported metanil yellow in parboiled rice, turmeric powder and split pulse grains, and rhodamine (10-95 ppm), orange II (135-560 ppm) or auramine (15-400 ppm) in sweets and roadside foods. At present, flavor concentrates, natural colors (beta-carotene, riboflavin, caramel, annato, saffron, curcumin) and synthetic colors (brilliant blue FCF, carmoisine, erythrosine, fast green FCF, ponceau 4R, sunset yellow FCF, indigo carmine and tartrazine) are permitted up to100 ppm for all foods or $200 \mathrm{ppm}$ for canned products. During trading, malachite green or copper sulphite to crucifers, green peppers, leafy vegetables and eggplant, and Congo red and Sudan dyes to red peppers are added for retaining natural appearance and freshness [10]. Similarly, acidity regulators, anticoagulating agents, antifoaming agents, antioxidants, bulking agents, color retention agents, emulsifiers, flavors and flavor enhancers are routinely used in the manufacturing and processing units. These admixtures are not permitted under the Prevention of Food Adulteration Act, 1954 (Rule 26). Nevertheless, permission is granted to add amorphous silicon dioxide as anti-caking agent in various infant foods, and butylated hydroxyl anisole as antioxidant in edible oils and fatty preparations, cereal products, biscuits and the breakfast foods. Currently, additives commonly mixed in the market yards include fat soluble azo dye to mustard oil, monosodium glutamate to meat and Chinese foods, sulphur dioxide to preserved foods, artificial sweeteners/sugar substitutes to sweets; 3,4 benzopyrene to smoked foods; cotton seed oil containing gossypol to edible oils, all are found beyond the safe limit [40].

\subsection{Food contamination}

Metals particularly lead, mercury and arsenic have been introduced in sweets and snacks; the main sources being soil and water. In fact, a little dose of metals is essential for body growth, but over dose produces toxic effects, and often, metals are not fully excreted. The vegetables grown in the vicinity of the brick kiln industries and national highways contain high levels of heavy metals [34]. In eastern India, West Bengal state is endemic to poisoning of lead and arsenic through contaminated ground water [27]. While sampling, Dahiya et al. [6] have found the cadmium (0.001-2.73 ug/g), nickel (0.041-8.29 ug/g) and lead (0.049-8.04 ug/g) in chocolates and candies; maximum being in cocoa-based chocolates. However, silver foil (made by beating pieces of pure silver in a very thin film) with purity of $99 \%$ can lawfully be used for wrapping sweets and snacks. In vegetables, average metal content was found 21 times higher than the natural level with maximum lead content of $185.64 \mathrm{ug} / \mathrm{g}$ (average $53.87 \mathrm{ug} / \mathrm{g}$ ) making the fourth abundant metal detected in India [8]. 
Several types of pesticides used against the field and household pests contaminate daily foods, and nearly $20 \%$ of food products containing pesticide residues [23]. When seeds are treated with mercury chloride (fungicide), fishes can take mercury with contaminated water. Similarly, whenever nitrogenous fertilizers are applied to vegetables, the harvested produce containing nitrites and nitrates enter the human body [27]. Besides, residue of the banned insecticides such as, aldrin, chlordane, and heptachlor, are applied to crops resulting in residue unknowingly remaining on/in food grains, vegetables and fruits. For example, higher residues than MRL of chlorpyriphos in cauliflower and rice, and quinalphos in cardamom have been reported by Mishra [28]. Residues of endosulfan, cypermethrin, dimethoate, monocrotophos and mancozeb were detected in $33.3 \%$ of samples of tomato, $73.3 \%$ of eggplant, $14.3 \%$ of okra, $88.9 \%$ of cabbage and $100 \%$ samples of cauliflower collected in the market [9]. Highest traces of chlorpyriphos [28] in over 10\% of market samples in Himachal Pradesh [21] and 92\% of samples in Punjab exceeded MRL fixed for DDT in milk [4]. Similarly, nearly $73 \%$ of the milk samples were having oxytetracycline residue in the range of $0.2-6.7 \mathrm{ug} / \mathrm{ml}$ and gentamycin in the range of $40-80 \mathrm{ug} / \mathrm{ml}[39,40]$.

Mycotoxins are produced by bacteria and fungi. The common fungi belonging to genera Aspergillus, Penicillium, Fusarium produce aflatoxins, fumonisins, ochratoxins, cyclopiazonic acid, nivalenol, patulin, zearalenone that are present in Indian foods [22]. Containers, metal machinery and plates used during food processing, handling, cooking, servicing and packaging are common sources of contamination in the hotels and restaurants where two bacterial species, Listeria monocytogenes and Clostridium botulinum have emerged and re-emerged [11]. In residential complexes where the sanitation facilities are poor, certain protozoa species (Cryptosporidium parvum, Toxoplasma gondii, Clonorchis sinensis), Norwalk virus and Hepatitis-A can infect home foods [11]. Sudershan et al. [40] mentioned presence of aflatoxin $(0.1-1 \mathrm{ug} / \mathrm{ml})$ in milk and red peppers. In the market, infant foods have been found with aflatoxin-1[32] and coffee with ochratoxins (5 ug/kg) [40]. Likewise, Singh and Sumbali [36] reported content of aflatoxin-B1 in marketed apple (312-1405 ug/kg) and pear (74-1280 ug/kg) which is far greater than tolerance limit (20 ppb). Poisoning from rice consumption occurs if it is contaminated with fungus species of the genera Penicillium, Fusarium, Rhizopus and Aspergillus [18]. There have been incidences of toxins A, B, E, F of Clostridium botulinum in canned or fermented foods, meat, sausages and smoked fish [38]. Infection of Clostridium perfringens (type A) in canned meat/fish; and enterotoxins A, B, C, D, E of Staphalococcus aureus in baked foods, dairy products, meat products and frozen foods, Bacillus cereus in cereal products, custard powder, puddings and sauces, and wheat bread covered with blackish fungal growth are common contaminants in weekly markets [18]. In places with poor sanitary conditions, milk and foods are contaminated with Aspergillus lumbriocoides, rodent urine through which Mapucho virus is disseminated, or virus-A present in human faeces or urine [18]. This finding is relevant to situations where defecation in the open space is still prevailing in some Indian villages. Rotten eggs, chicken, meat or meat products contain botulin toxin via infection of a bacterium, C. botulinum. Uncooked meat/pork is infected by Salmonella spp., Shigella sonnei or Listeria spp. [18, 27]. In reality, fungal infection may occur in the field and then carried further to foods. For example, broken, insectdamaged and diseased peanuts generally attract two fungal species (Aspergillus flavus and A. parasiticus). The pearl millet and rye grains are infected during grain development and after harvest, by ergot disease fungi (Claviceps fusiformis, $C$. purpurea) which liberate ergotoxins (containing peptide alkaloids, lysergic acid and lysergic acid amides) [37]. Recently, Sarathchandra and Muralimanohar [33] reported high occurrence of citrinin followed by ochratoxin-A and aflatoxin-B1 in animal feeds and feedstuffs. Further, Salmonella typhimurium DT-104 strain resistant to several antibiotics is widely distributed in cattle herds.

The food service industry contributes $60-80 \%$ of the food-borne diseases in India [24]. The roadside fast foods, including Chinese recipes are popular in urban areas where little attention is bestowed on hygiene, food safety or nutritional quality, and regulation compliance is poor. For example, water, juice of sugarcane or lime and ice have significantly higher load (6.5 cfu/100 ml) of S. aureus, Vibrio spp., Shigella spp., Salmonella spp., Bacillus cereus and fecal coliforms [26, 38]. Most of the street foods contain nitrites, meta-sulphites and monosodium glutamate used as preservatives [18].

\subsection{Food from genetically modified crops}

In India, over 20 Genetically modified (GM) food crops including cereals, oilseeds, vegetables and fruits are being field tested for various traits including those for nutritional quality and for pest and disease control [14]. Currently, the first ever food crop, eggplant, to be cultivated by farmers is in controversy. Farmers, NGOs, private companies, consumers, industries, scientists, policy makers and government ministries are debating although the Genetic Engineering Appraisal Committee strongly recommended it. The central government is not conducive to promoting GM crops probably because more research on human health, environmental and economic risks, is needed before full scale adoption. There is increasing demand for non-GM foods and food products from consumers who are aware about the widespread prevalence of GM organisms in the food supply chain and their ill effects after consumption [14, 15]. Few shopping guidelines have been recently prepared by organizations (viz. Green Peace, Gene Campaign, and IFOAM) which are actively working on this mandate. In future, the intellectual property rights and labeling would pose difficulties in near future because there is no system of trace-back of ingredients used in a product. Most of the foods sold in loose form in 
the market are liable to be degraded in the processed/final product. Recently, the Department of Consumer Affairs under the Food \& Consumer Affairs Ministry mandated that all packaged food products containing GM ingredients should carry a label from January 2013, under the Legal Metrology (Packaged Commodities) Rules. These include baby foods, biscuits, breads, edible oils, milk powder, cereals and pulses. The central government also decided to establish the GM Foods and Food Safety Assessment Unit with multi-disciplinary team of scientists.

\section{Implication of food adulteration and contamination}

Sudershan et al. [40] reviewed the literature published during 1995 - 2005 on the situation of food safety in India and opined that incidence of food-borne diseases that are non-epidemic and not recognized either by the public or the health authorities, had not been reported due to lack of data. One of the reasons is that various diseases are not categorized separately in the health statistics, though about $70 \%$ of deaths are supposed to be of food-borne origin [40]. Recently, the Safe Food International gathered limited data on food poisoning reported during 2007-11 (http://regionalnews.safefoodinternational.org). This report showed that major sources of contamination are the daily meals $(57 \%)$, sweets $(13 \%)$ and mid-day meals in schools $(11 \%)$. Besides, feeds used in animal husbandry and fish farming when contaminated with mycotoxins resulted in the carry-over of toxins to consumers through milk and meat. Eventually, the effects of food adulterants and contaminants had to be determined in the context of their effects on human health and detection in daily foods $[7,11,18]$.

In 1988, 600 persons in Kolkata (West Bengal) suffered from paralysis in hands after having consumed the rapeseed oil adulterated with tricresyl phosphate which is generally used in varnishes and hydraulic fluid. Adulteration of mustard oil with Mexican prickly poppy/argemone (Argemone mexicana) oil caused dropsy in Delhi in 1998, Gwalior (Madhya Pradesh) in 2000, and Kannauj and Lucknow (Uttar Pradesh) in 2002 and 2005 respectively. Various clinical symptoms were obvious and in severe cases, death occurred due to cardiac and respiratory failure [12]. Lately, the Food and Safety Standards Authority of India published the report of the national survey of adulterated foods in 33 states, viz. $8.79 \%$ incidence $(n=94,000)$ in $2008 ; 11.14 \%(n=113,000)$ in $2009 ; 12.65 \%(n=117,000)$ in 2010 . When milk samples $(n=1791)$ collected in New Delhi were tested, $32 \%$ of them were found diluted with water, or mixed with glucose/skim milk powder $(30.6 \%)$ or harmful detergent (5.7\%) [12]. Around 44\% samples of peanut oil were found adulterated with $5-20 \%$ of cotton seed oil, palm oil or castor oil consumption of which resulted in food-borne diseases and $70 \%$ of children died with diarrhea [40]. This type of contamination comes mainly from supply chain and poor sanitary conditions in the markets where food stocks and storage structures remain unchecked and unregulated. On an average, $13 \%$ of both packaged and loose food items sold across the country have been found contaminated; and the range varied considerably from one state to another, i.e., Chandigarh (40\%), Uttarakhand (34\%), Uttar Pradesh (29\%), Rajasthan (23\%), West Bengal \& Himachal Pradesh (20\%), Bihar (17\%), Nagaland (16\%), Madhya Pradesh, Odisha \& Punjab (15\%), Tamil Nadu (14\%), Maharashtra (10\%), Karnataka (5\%) and Delhi (4\%) [12]. In another survey, $70 \%$ of milk samples did not confirm to prescribed standards; i.e., $46 \%$ were with low solid not fat due to dilution with water, and $8 \%$ were with detergents [28].

\section{Safety measures}

\subsection{Producers and manufacturers}

At field level, for avoiding food contamination of agricultural produce, before and after harvest, there is need for a shift by adopting Good agricultural practices (GAP) including integrated pest management. Over and indiscriminate doses of synthetic fertilizers and pesticides should be replaced by need-based applications of safe and recommended pesticides. These practices would help in reducing chemical use in general and in controlling aflatoxin in particular [20]. Contamination of Aspergillus flavus in peanut can be controlled by Trichoderma spp. which are potent antagonists producing volatile and diffusible antibiotics [37]. Other effective ecofriendly measures include spraying with a mixture of water extract (5\%) of pongam (Pongamia pinnata) bark or tamarind (Tamarindus indica) fruit [5]. Severity of fungal infection can also be lowered by spraying water extract (5\%) of leaves of neem, henna (Lawsonia inermis), or turmeric (Curcuma longa) powder [1].

In manufacturing industries, wearing of personal protective clothes, gloves and washing of whole body after working hours is the best practical remedy to avoid contact with chemicals. Moreover, safe period recommended before crop harvest is to be respected rigorously and the prescribed norms including antidotes and preventive measures have to be followed [13]. In industrial areas, dumping of poisonous effluents needs to be avoided. Other preventive measures include strict control on various sources of contamination, regular follow up by authorities for recommended food standards and labelling. In case of doubt, simple chemical tests can confirm the content of contaminants [11]. To safeguard consumers, locally and globally, from residues of chemicals, the MRL has been fixed for each crop or food product by Codex Alimentarius Commission (CAC) which is an apex body of FAO and WHO. 


\subsection{Consumers}

Prevention of admixture is possible while purchasing food, by adopting simple means at household level and by reporting to concerned authorities. It is better to check the quality of food grains at the time of purchase and only branded and ISI marked products should be preferred. One should reject artificially colored rice, pulses, sweets, spices, junk food, adulterated milk or oil. The fruits which are just slightly under-ripe and not over-ripe should be purchased to stagger the ripeness. At home, whole grains (cereals and pulses), spices and condiments can be sorted out manually from admixture. Otherwise, grains can be sieved and foreign materials including sand, pebbles or dirt particles can be easily discarded. In fact, this is an age-old household practice followed by rural people in India. In case of fruits, peeling can remove wax coating containing toxic material. Moldy grains may contain fumonisin toxin-B1 produced by Fusarium moniliforme or F. verticilliodes. These grains should not only be separated and discarded but also properly destroyed. Parboiling of grass pea grains and washing with fresh water is helpful in removing $>90 \%$ of toxin (Beta-noxalyl amino alanine, BOAA) [15]. Food grains and nuts should be dried immediately after crop harvest and stored in clean, dry and cool place to prevent mold development. The grains showing caking during storage may be dried again. Irrespective of this measure, whenever the mold growth is noticed, never scrape it off and eat the remaining grains. Instead, these grains must be burnt or buried and not simply discarded. Cleaning for extraneous matter, insect damaged and visible moldy grains can reduce the level of contamination during handling of raw material. Washing of grains four times with gentle rubbing of grains and drawing water after each wash followed by cooking can remove $>95 \%$ of residues of malathion, methyl parathion, fenvalerate, cypermethrin or chlorpyriphos [29]. Thus, processing (washing, drying and milling) and cooking can help to prevent incidental poisoning.

Consumers should purchase canned foods after verifying expiry date and never purchase exposed foods, ice and juice sold in open market that are often suspected to be contaminated. Containers should be washed with soap and hot water before pouring juice or transferring food. In case of doubt, infection of coliform bacteria on fruits and vegetables can effectively be controlled with plant extracts in water [30] or petroleum ether ( 2 ug ml-1) of moringa (Moringa oleifera) leaves [31]. Similarly, fruits and vegetables should be washed properly or peeled them off to remove the chemical contaminants deposited on them. Pesticide residues are adsorbed or deposited in waxy layer of the soft fruits and vegetables, those with high fat content should therefore be avoided. Washing vegetables and fruits in $2 \%$ salt solution for 10 minutes followed by rinsing 2-3 times in cold water can get rid of much of toxins [13]. It has been ascertained that the cooked food is safer than the raw food as cooking process reduces the residual amount of contaminants by degradation and detoxification [13]. However, cooked food stored for several hours in the open space or refrigerated for a long time can favor bacterial growth because depending upon type of food, refrigeration generally inhibits mold growth but does not deter it completely. It is therefore wise to reheat the stuff before serving. For this purpose, improved cooking methods would prove advantageous; for example, cooking for a long time or at high temperature destroys bacteria and reduces aflatoxin content; cutting meat into small pieces ensures thorough penetration of heat. Boiling milk at high temperature or heating oil up to a particular flash point can degrade/detoxify the persistent pesticide residues [15].

Consumers and social organizations should send samples of vegetables, fruits; food grains etc. to local testing laboratories and lodge the complaint with local municipality or civil authorities. The action taken against defaulters would provoke others to fight against adulteration and contamination. In tribal areas, food provided in school and college canteens by the All India Food Processors Association and other agencies was not up to standard and was often rejected by children. In such cases, the consumer education programs play an important role in imparting knowledge on the purchase and use of safe foods. Likewise, strong enforcement mechanisms, effectiveness of civil society groups and close liaison between local and state bodies can facilitate the follow-up of the uniform implementation of the food laws. For this, vibrant consumer movement at national level particularly by senior citizens, ladies clubs and NGOs can result in some progress.

\section{Role of government agencies}

\subsection{Market surveys}

Market surveys of the dangerous build-up of toxins in food help prevent incidental poisoning. The health authorities can keep watch on illegal activity pertaining to ethylene or oxytocin in vegetables and fruits, and dyes or acids in edible oil. It is mandatory to declare the colour on the label of container. Therefore, admixtures of various colors should be checked regularly by market surveys and sampling by the Public health inspectors. For the animal feeds with additives (diethyl silbestrol, nitrites, nitrates, antibiotics) sold, competent authorities can execute current regulations. However, metal detection is certainly difficult by illiterate consumers. Therefore, sampling and verification of content should only be done by competent authority and samples sent to the recommended laboratory. 


\subsection{Inspection and testing}

The existing food chain is complex, adaptive and efficient but the infrastructure connecting various stakeholders is rather weak and scattered. As such, there are only a few real channel masters who can manage the supply-demand situation, coordinate whole supply chain and supervise logistic activities. Regular food sampling and testing at the retail level can ensure that shops store only safe foods and remove from the shop-selves other foods seemed unfit for consumption. The reality is that the demand forecasting is nearly non-existing and farmers try to push into market what they produce. Recently, cold chain has been introduced in the food supply system to maintain ideal storage conditions for perishables from the point of origin to the point of human consumption. A well-organized cold chain can therefore reduce spoilage, can retain the quality of the harvested produce and can guarantee a cost- efficient delivery to the consumer with adequate attention to the customer services. Along with cold chain, the supply chain is required to be designed and built in an integrated manner using the processes of product development, and efficient procurement supported with adequate information technology and software packages.

Food safety measures are of utmost importance to food producers, retailers, public authorities and health inspectors. Nowadays, food safety programs are focusing on a "farm to table/farm to fork" approach as an effective means of reducing food-borne diseases. Thus, the data on integration, financial flow management, supply-demand matching, collaborative forecasting, information-sharing and food movement synchronization in supply chain are needed to facilitate current food control. Recently, Lala Lajpat Rai University of Veterinary and Animal Sciences, Hisar (Haryana) developed a kit for rapid spot testing to detect urea in milk. The irradiation of foods and food products as post-harvest treatment can be combined with regulatory measures at both national and international levels to prevent contamination and make the food safe. The National Monitoring Agency vested with powers decides policy issues on food irradiation and has the responsibility of regular surveillance and monitoring for food safety. The Hazard analysis critical control point (HACCP) system has now been introduced to identify, evaluate and control hazards arising from crop harvest until the point of consumption. Recently, Luo et al. [25] recommended application of a loop-mediated isothermal amplification assay for rapid identification of aflatoxin-producing molds. Likewise, two multiplex polymerase chain reaction assays has been effective to detect genes of five types of $E$. coli [17]. On the contrary, the traditional quality control system was relying mostly on end-food hygiene-HACCP system with guidelines for application as ISO-15000 in 1998. In addition to four central laboratories, state governments and municipal councils/corporations in cities have their own laboratories to handle the food adulteration and contamination. In future, checking for quality marks such as ISI, Food Products Order (FPO/AGMARK), and follow up of labeling directions should be a regular practice. In reality, it is difficult to monitor quality of the processed foods in small cottages or household manufacturing/processing units in rural areas where strict adherence to the rules and regulations is always needed. Therefore, the Food Inspectors and Public Food Analysts are authorized for launching prosecution.

\subsection{Regulation and certification}

Food adulteration is often linked with impurities in the food grains sold through the Public distribution system (PDS), the only food supply agency under central government. Proper enforcement of the regulations is lacking and most state governments do not have the machinery to conduct checks from time to time. Likewise, spoilage, sanitation and contamination of food have not been given requisite attention by health authorities. Therefore, concept of the Food safety objective developed by FAO and WHO should be introduced and form an integral part of food chain management $[2,16]$.

The inspection and certification are done by the Bureau of Indian Standards (BIS) under the Directorate of Marketing and Inspection (DMI). The BIS operates the ISI (Certification marks) Act of 1952 which had laid down the quality standards for processed foods supported by testing methods for almost all consumer goods. The ISI certification though voluntary, becomes mandatory under certain acts. The AGMARK standard has been revised by the DMI and the Agriculture Produce Act has been introduced under which the government fixes the quality specifications. The Central Committee for Food Standards is the primary policy making body which advises government on application of specifications, quality control inspection and testing whereas the Food Safety and Standards Authority of India is an autonomous statutory authority under administrative control of the Ministry of Health and Family Welfare. It regulates the manufacturing, storage, distribution, sale and import, and thereby, insures availability of safe food for human consumption. Recently, formation of the National Food Quality Control Board has also been suggested by the government. Also, Ministry of Health and Family Welfare has constituted a National Codex Committee, and has established the National Food Science and Risk Assessment Centre for carrying out analysis of food surveillance data recorded from laboratories in order to generate data on food hazards and outbreaks of food borne diseases and to implement the codex-adopted general principles of food hygiene and recent guidelines for hazard analysis. These data would be helpful in prevention, intervention and control of at least major cases. For detecting contamination of the food-borne diseases caused by microorganisms, modern laboratory facilities with pollution control measures, food quality inspection, and monitoring and management (including treatment, packaging and preservation) are needed. For 
facilitating this program, the central government recently planned to set-up cluster laboratories of accredited standards for every 4-5 districts to carry out basic tests and zonal food laboratories (1 for 10 districts) to perform tests for residues and heavy metals and 10 referral laboratories for reference.

The export of Indian foods to the Middle-East, Europe, Australia and the USA is on increase. In some consignments, foods are rejected due to sub-standard supply. Thus, there is need to revamp food supply chain and regulatory agencies such as, Agricultural and Processed Food Products Export Development Authority. On legal front, Indian government established certain laws and rules for prevention of food adulteration and contamination in food service establishments and the amendments are regularly published in gazettes by the Food and Drug Administration concerning Prevention of Food Adulteration Act 1954 (8th amendment in 2008); Prevention of Food Adulteration Rules 1955 (1st amendment in 2011); Export (Quality Control and Inspection) Act 1963; Indian Consumers Protection Act 1968; The Insecticides Act 1968; Meat Food Products Order 1973; Hazardous Chemicals Rules 1989; Milk and Milk Products Order 1992; Fruit Products Order 1995; Food Safety and Standards Act 2006; Food Safety and Standards Authority of India 2008; Food Safety and Standards rules 2011. Further, the Consumer Protection Act makes the public aware of food contamination and prevention of fatal incidents. Also, Consumers Association of India and Consumers Education and Consumers Guidance Society of India collaborate actively with government and voluntary organizations. In addition to this national network, international support is sought through WHO/FAO International Food Safety Authorities Network, Codex Committee on Food Additives and Codex Committee on Contaminants in Food.

It is generally expected that the guidelines of the management systems are in the compliance with HACCP [8]. In future, international co-operation, information-sharing mechanism, dialogue between stakeholders, involvement of private sector, labeling and tracking systems for traceability, all can strengthen the existing rules and regulations. India being a signatory to the World Trade Organization, it becomes a party to the related agreements which lay emphasis on the CAC decisions. The CAC adopted general principles of food hygiene as an international code of practice. Likewise, the WHO's Food Contamination Monitoring and Assessment Program has encouraged developing countries to undertake total diet studies as a matter of public health significance. For example, the enterprise resource planning is designed to track products in lots during food processing for admixture of additional ingredients, portioning and transformation. Imparting training to food handlers including kitchen staff in basic hygienic practices will facilitate garbage disposal and strengthen official control over the quality and safety of foods served on streets and in open-air food stalls [8]. Recently, Lin [24] examined regulatory systems and described difficulties that international organizations encounter and has advocated reforms to improve the international governance strategy of food safety

\section{Conclusion}

There is little data about the connection between food adulteration and contamination and its effect on human health (mainly concerning with food-borne diseases). In rural areas, this problem is more distressing than in urban zones. Therefore, awareness campaigns and monitoring agencies of the government can alert for accidental poisoning at village level. Attention is also needed to fight against increasing resistance in bacteria that cause morbidity and diseases. The concerned institutions particularly, All India Institute of Hygiene \& Public Health and Indian Council of Medical Research, should conduct research on basic and applied aspects and publish findings on expected risk of human diseases due to adulterated and contaminated foods. Since consumers are at the end of food chain, they should form associations and fight for their rights to get safe foods. In fact, with rapid growth in urbanization, the consumerism, food processing and marketing systems have been changed significantly. More attention is thus needed for further extension of improved practices in agriculture and animal husbandry, measures to prevent and control pre- and post-harvest losses, more efficient food processing and distribution systems, and application of biotechnological techniques to make food not only readily available but free from adulteration and contamination.

\section{References}

[1] R.K. Bansal, A.K. Sobti, An economic remedy for the control of two species of Aspergillus on groundnut, Indian Phytopathology 43 (1990) 451-452.

[2] N. Barro, A.R. Bellow, Y. Itsteimbou, A. Savadogo, C.A.T. Ouattara, A.P. Nikiema, C. De Souza, A.S. Traore, Street-vended foods improvement- contamination mechanisms and application of food safety objective strategy: Critical review, Pakistan Journal of Nutrition 6 (2007) 1-10.

[3] R.V. Bhat, Food Safety Evaluation: National and International Perspectives. Nutrition Foundation of India, New Delhi, India, 1997.

[4] R.V. Bhat, P.H. Shetty, R.P. Amruth, R.V. Sudershan, A food borne disease outbreak due to consumption of mouldy sorghum and maize containing fumonisin mycotoxins, Journal of Toxicology \& Clinical Toxicology 35 (1997) 249-255.

[5] H. Chandra, O.P. Sidhu, J. Srivastava, N. Rai, S.V.S. Chauhan, A. Singh, A.R. Nautiyal, Synergistic effect of Pongamia pinnata bark and Tamarindus indica fruit extract against aflatoxin producing fungus, i.e. Aspergillus flavus. Environment Conservation Journal 8 (2007) 101107

[6] S. Dahiya, R. Karpe, A.G. Hegde, R.M. Sharma, Lead, cadmium and nickel in chocolates and candies from suburban areas of Mumbai, India Journal of Food Composition and Analysis 18 (2005) 517-522.

[7] M. Das, Food Safety. Indian Institute of Toxicology Research, Lucknow, India, 2011. 
[8] S. De, Food safety: Steps of rising concern, Everyman's Science 65 (2010) 219-222.

[9] M.D. Dethe, V.D. Kale, S.D. Rane, Possible residues in/on farm gate samples of vegetables, Pest Management in Horticultural Ecosystems 1 (1995) 49-53.

[10] S. Dixit, R.C. Pandey, M. Das, S.K. Khanna, Food quality surveillance on colours in eatables sold in rural markets of Uttar Pradesh, Journal of Food Science and Technology 32 (1995) 373-376.

[11] FAO, Assuring Food Safety and Quality: Considerations of Food Safety and Consumer Protection. FAO Corporate Document Repository, Agriculture and Consumer Protection Division, Food and Agriculture Organization, Rome, Italy, 2011. (http://www.fao.org/docrep/006/y870e/y870e09.html).

[12] FSSA, Food Safety and Standards Authority of India, Ministry of Health and Family Welfare, Government of India, New Delhi, India, 2011.

[13] R.T. Gahukar, Agro-medical Guide of Synthetic Pesticides, 1st edn., Agri-Horticultural Publishing House, Nagpur, India, 1999.

[14] R.T. Gahukar, Are Indian foods from genetically modified crops safe? International Journal of Food, Agriculture \& Environment 2 (2004) 1113.

[15] R.T. Gahukar, Adulterated food, Kisan World 36(8) (2009) 33

[16] L.G.M. Gorris, Food safety objective: An integral part of food chain management, Food Control 16 (2005) 801-809.

[17] A. Hegde, M. Ballal, S. Shenoy, Detection of diarrheogenic Escherichia coli by multiplex PCR, Indian Journal of Medical Microbiology 30 (2012) 279-284.

[18] P.K. Jaiswal, Common Adulterants/Contaminants in Food and Simple Screening Tests for Their Detection, Central AGMARK Laboratories, Nagpur, India, 2011.

[19] G.R. Janardhana, K.A. Raveesha, H.S. Shetty, Mycotoxins contamination of maize grains grown in India (Karnataka), Food Chemistry and Toxicology 37 (1999) 863-868.

[20] G.D.S. Kumar, M.N. Popat, Farmers' perceptions, knowledge and management of aflatoxins in groundnuts (Arachis hypogaea L.) in India, Crop Protection 29 (2010) 1534-1541.

[21] N.R. Kumar, A. Nath, Monitoring bovine milk for DDT and HCH. Pesticide Research Journal 8 (1996) 90-92.

[22] V. Kumar, M.S. Basu, T.P. Rajendran, Mycotoxin research and microflora in some commercially important agricultural commodities, Crop Protection 27 (2008) 891-905.

[23] D. Kurup, Mercury for Lunch, Lead for Dinner. The Hindu, issue of July 8 (pp. 1-2), Bangalore, India, 2009.

[24] C.F. Lin, Global food security: Exploring key elements for an international regulatory strategy, Virginia Journal of International Law Association 51 (2011) 637-694.

[25] J. Luo, P.F. Vogel, L. Niessen, Development and application of a loop-mediated isothermal amplification assay for rapid identification of aflatoxigenic molds and their detection in food samples, International Journal of Food Microbiology 159 (2012) 214-224.

[26] D.P. Mahale, R.G. Khade, V.K. Vaidya, Microbiological analysis of street-vended fruit juices from Mumbai city, India, Internet Journal of Food Safety 10 (2008) 31-34.

[27] S. Majumdar, Food hazards and food security, Everyman's Science 64 (2010) 348- 355

[28] S.S. Mishra, Pesticide-rich food, Down To Earth 19(18) (2011) 16.

[29] K.P. Nair, T.B. Mathew, Home processing to address food safety issues in cereals, Journal of Insect Science, 26 (Special issue) (2013) 111119.

[30] P.S. Negi, Plant extracts for the control of bacterial growth: Efficacy, stability and safety issues for food application, International Journal of Food Microbiology 156 (2012) 7-17.

[31] M.M. Rahman, S. Akhter, M. Jamal, D.R. Pandeya, M.A. Haque, M.F. Alam, Control of coliform bacteria detected from diarrhea associated patients by extracts of Moringa oleifera, Nepal Medical College Journal 12(1) (2010) 12-19.

[32] S. Rastogi, P.D. Dwivedi, S.K. Khama, M. Das, Detection of aflatoxin M-1 contamination in milk and infant milk products from Indian markets by ELISA, Food Control 15 (2004) 287-290.

[33] G. Sarathchandra, B. Muralimanohar, Occurrence of mycotoxins in livestock feeds and feedstuffs of Tamil Nadu, Journal of Environmental Biology 34 (2013) 825-830.

[34] K. Sharma, P.P. Dhyani, S.S. Samant, Toxic chemicals in fruits and vegetables: An overview, Everyman's Science 65 (2010) $215-218$.

[35] M.W. Sidiqui, R.S. Dhua, Eating artificially ripened fruits is harmful, Current Science 99 (2010) 1664-1668.

[36] Y.P Singh, G. Sumbali, Aflatoxin B1 contamination in commercial varieties of apple and pear fruits with Aspergillus flavus Link ex Fries, Indian Phytopathology 64 (2011) 100-101.

[37] P. Srilakshmi, R.P. Thakur, K. Satyaprasad, Mechanism of biocontrol of Aspergillus flavus in groundnut by species of Trichoderma, Journal of Mycology \& Plant Pathology 41 (2011) 249-254.

[38] K. Subbannayya, G.K. Bhat, S. Shetty, V.G. Junu, How safe is sugarcane juice? Indian Journal of Medical Microbiology 25 (2007) $73-74$.

[39] R.V. Sudershan, G.K. Bhat, A survey on veterinary drug use and residues in milk in Hyderabad, Food Additives and Contaminants 12 (1995) 645-650.

[40] R.V. Sudershan, P. Rao, K. Polasa, Food safety research in India: A review, Asian Journal of Food \& Agro-Industry 2 (2009) $412-433$.

[41] WHO, Evaluation of Certain Food Additives and Contaminants, 67th Report of the Joint FAO/WHO Expert Committee on Food Additives, WHO Technical Report Series no. 940, World Health Organization, Geneva, Switzerland, 2007. 